Muhammad Salman Faisal, MD; Tavankit Singh, MD; Hina Amin, MD; Jamak Modaresi Esfeh, MD

Department of Internal Medicine (Dr. Faisal) and Department of Gastroenterology, Hepatology and Nutrition (Drs. Singh, Amin, and Modaresi Esfeh), Cleveland Clinic, Ohio

- faisalm@ccf.org

The authors reported no potential conflict of interest relevant to this article.

doi: 10.12788/jfp.0186

\title{
A guide to diagnosing and managing ascites in cirrhosis
}

\author{
Combined serum and ascites fluid measurements \\ point to the cause of ascites. For patients with modest \\ edema, a reduced weight-loss target with diuresis may be \\ acceptable.
}

\section{PRACTICE RECOMMENDATIONS}

$>$ Calculate the serum ascites albumin gradient and measure the total ascites protein level to distinguish cirrhotic ascites from that caused by heart failure or other disorders. (C)

> Recommend sodium restriction of 4.9-6.9 g for patients with established ascites secondary to cirrhosis. (C)

> Avoid giving angiotensinconverting enzyme inhibitors, angiotensin receptor blockers, and nonsteroidal anti-inflammatory drugs in cirrhosis. C

Strength of recommendation (SOR)

A Good-quality patient-oriented evidence

B Inconsistent or limited-quality patient-oriented evidence

C Consensus, usual practice, opinion, disease-oriented evidence, case series
$\mathrm{L}$ iver cirrhosis is implicated in $75 \%$ to $85 \%$ of ascites cases in the Western world, with heart failure or malignancy accounting for fewer cases. ${ }^{1}$ Among patients who have decompensated cirrhosis with ascites, annual mortality is $20 \% .^{2}$ Another study showed a 3-year survival rate after onset of ascites of only $56 \%{ }^{3}$ It is vital for primary care physicians (PCPs) to be alert for ascites not only in patients who have risk factors for chronic liver disease and cirrhosis-eg, a history of alcohol use disorder, chronic viral infections (hepatitis B and C), or metabolic syndrome-but also in patients with abnormal liver function tests and thrombocytopenia. In this review, we discuss the initial assessment of ascites and its long-term management, concentrating on the role of the PCP.

\section{Pathophysiology:}

\section{Vasodilation leads to a cascade}

Splanchnic vasodilation is the main underlying event triggering a pathologic cascade that leads to the development of ascites. ${ }^{4}$ Initially portal hypertension in the setting of liver inflammation and fibrosis causes the release of inflammatory cytokines such as nitric oxide and carbon monoxide. This, in turn, causes the pathologic dilation of splanchnic circulation that decreases effective circulating volume. Activation of the sympathetic nervous system, vasopressin, and reninangiotensin-aldosterone system (RAAS) then causes the proximal and distal tubules to increase renal absorption of sodium and water. ${ }^{5}$ The resulting volume overload further decreases the heart's ability to maintain circulating volume, leading to increased activation of compensating symptoms. This vicious cycle eventually manifests as ascites. ${ }^{6}$

A complex interplay of cirrhosis-associated immune dysfunction (CAID), gut dysbiosis, and increased translocation of microorganisms into ascitic fluid is also an important aspect 


\section{Mechanisms of cirrhosis-associated immune dysfunction (CAID) $)^{7,8}$}

Damage to hepatocytes, gut dysbiosis, and increased bacterial translocation expose the compromised host immune system to pathogen-associated molecular patterns and damage-associated molecular patterns. Translocated bacteria activate inflammatory cells in gut-associated lymphoid tissue and mesenteric lymph nodes. This causes parallel processes of widespread systemic inflammation, hemodynamic disturbances, and endothelial activation contributing to many complications of cirrhosis, including ascites. A decrease in the ability to act against pathogens, combined with poor clearance by the reticuloendothelial system, leads to increased susceptibility to infections, including spontaneous bacterial peritonitis.

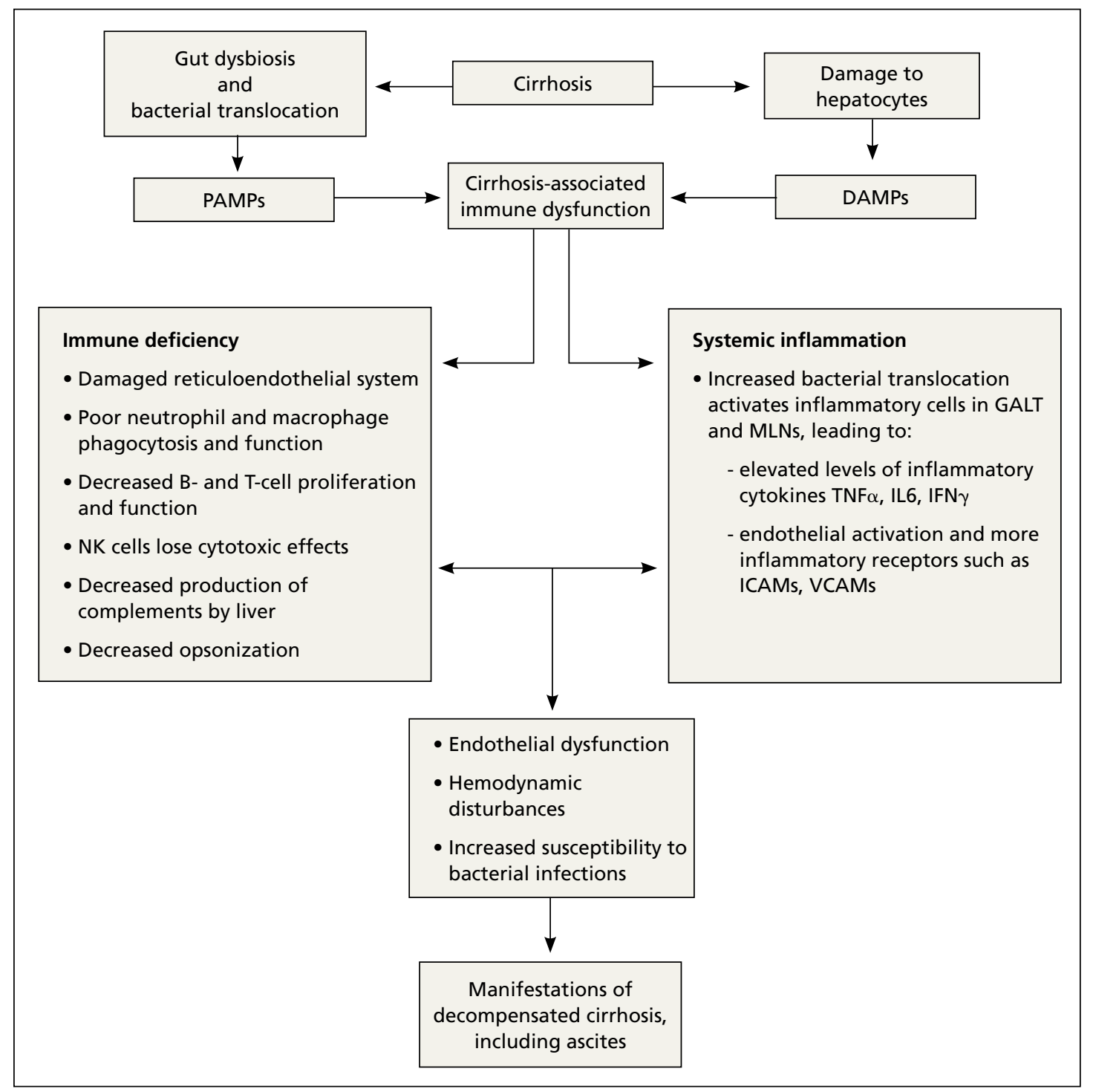

DAMPs, damage-associated molecular patterns; GALT, gut-associated lymphoid tissue; ICAMs, intercellular adhesion molecules; MLNs, mesenteric lymph nodes; NK, natural killer; PAMPs, pathogen-associated molecular patterns; VCAMs, vascular cell adhesion molecules.

of the pathogenesis. ${ }^{7}$ CAID (FIGURE 1$)^{7,8}$ is an immunodeficient state due to cirrhosis with reduced phagocytic activity by neutrophils and macrophages, T- and B-cell hypoproliferation, and reduced cytotoxicity of natural killer cells. In parallel, there is increased production of inflammatory cytokines due to the effects of damage-associated molecular patterns (DAMPs) from hepatocytes and pathogen-associated molecular patterns (PAMPs) from the gut microbiota on the immune system, which leads to many of the manifestations of decompensated cirrhosis including ascites. ${ }^{8}$ 


\section{TABLE}

\section{Initial work-up for possible cirrhosis-associated ascites}

\begin{tabular}{l|l}
\hline History & $\begin{array}{l}\text { - Ask about abdominal fullness, recent weight gain, ankle edema. } \\
\text { - Ask about risk factors for liver disease and ascites: alcohol abuse; features of metabolic syndrome; } \\
\text { drug use; unsafe sexual practices; history of travel; history of cardiac, renal, or thyroid disease; or } \\
\text { malignancy. }\end{array}$ \\
\hline Physical exam & $\begin{array}{l}\text { - Check for distended abdomen, flank dullness, positive shifting dullness, and fluid thrill. } \\
\text { - Look for signs of chronic liver disease: spider angiomas, jaundice, caput medusae, tremor/asterixis, } \\
\text { palmar erythema, gynecomastia. }\end{array}$ \\
\hline Labs, imaging & $\begin{array}{l}\text { - Order blood tests: complete blood count, comprehensive metabolic panel, prothrombin time/ } \\
\text { international normalized ratio. }\end{array}$ \\
\hline Paracentesis & $\begin{array}{l}\text { Consider ordering ultrasound to detect abdominal fluid, even if it's not clinically apparent; it can also } \\
\text { for paracentesis. A Doppler exam can detect patency of hepatic vasculature. }\end{array}$ \\
\hline - Check cell count and differential, albumin, and total protein on all samples. \\
- Calculate SAAG in ascitic fluid (see FIGURE 2).
\end{tabular}

SAAG, serum ascites albumin gradient.

\section{Key in on these elements} of the history and exam

Each step of the basic work-up for ascites provides opportunities to refine or redirect the diagnostic inquiry (TABLE).

\section{History}

Generally, patients with ascites present with weight gain and symptoms of abdominal distension, such as early satiety, nausea, and vomiting. Besides cirrhosis, rule out other causes of ascites, as treatment differs based on the cause. ${ }^{9}$ Also ask about histories of cancer and cardiac, renal, or thyroid disease. ${ }^{10}$

Patients with ascites in the setting of liver disease usually are asymptomatic in its early stages. Common complaints are vague abdominal pain, generalized weakness, malaise, and fatigue. ${ }^{11}$ Ask patients about risk factors for liver disease such as obesity, diabetes, hypertension, alcohol use, unsafe sexual practices, recent travel, and needle sharing or drug use. Due to a strong association between obstructive sleep apnea and fatty liver disease, consider screening at-risk patients for sleep apnea. ${ }^{12}$

\section{Physical exam}

When there are risk factors for liver disease, examine the patient for stigmata of cirrhosis and ascites. Signs of liver disease, aside from ascites, may include spider angiomas on the upper trunk (33\% of cirrhosis patients), ${ }^{13}$ gynecomastia ( $44 \%$ of cirrhosis patients), ${ }^{14}$ palmar erythema, jaundice, asterixis, and abdominal wall collaterals including caput medusa. ${ }^{15}$

We suggest a systematic and targeted approach to using various physical exam maneuvers described in the literature. If the patient has a full/distended abdomen, percuss the flanks. If increased dullness at the flanks is detected, check for shifting dullness, which indicates at least $1500 \mathrm{~mL}$ of fluid in the abdomen. ${ }^{16}$ Keep in mind that a $10 \%$ chance of ascites exists even if shifting dullness is absent. ${ }^{17}$ Maneuvers such as the puddle sign and fluid thrill are less accurate than shifting dullness, which has $83 \%$ sensitivity and $56 \%$ specificity in detecting ascites. ${ }^{17}$ Patients with cirrhosis also have a high likelihood of complications from ascites such as inguinal, umbilical, and other hernias.

\section{Diagnostic work-up}

includes blood tests and ultrasound

I Blood tests. The initial work-up for ascites should include complete blood count, complete metabolic panel, and prothrombin time/international normalized ratio. ${ }^{18}$

I Abdominal ultrasound is recommend- 
ed as the first-line imaging test. ${ }^{19}$ Aside from detecting ascites, it can give an estimate of the volume of ascites and indicate whether it is amenable to paracentesis. A vascular exam added to the standard ultrasound can detect radiologic evidence of portal hypertension such as splenomegaly, portosystemic collaterals, splenorenal shunt, patency of the paraumbilical vein, and portal vein diameter. Patients with established cirrhosis also require abdominal ultrasound every 6 months to screen for hepatocellular cancer. ${ }^{20}$

Abdominal paracentesis is the cornerstone of ascites evaluation. ${ }^{21}$ It is indicated for every patient with new-onset ascites or for any patient with known ascites and clinical deterioration. Ascitic fluid analysis can be used to easily differentiate portal hypertension from other causes of ascites. It can also be used to rule out bacterial peritonitis. The recommended sites for evaluation are in the left lower quadrant, $3 \mathrm{~cm}$ cranially and $3 \mathrm{~cm}$ medially from the anterior superior iliac spine..$^{22}$ A large cohort study showed that abdominal ultrasound-guided paracentesis reduced bleeding complications by $68 \%$ following the procedure and is strongly recommended (if available). ${ }^{23}$ Generally, paracentesis is a relatively safe procedure with a low risk of complications such as abdominal wall hematoma (1\%), hemoperitoneum $(<0.1 \%)$, bowel perforation $(<0.1 \%)$, and infection $(<0.1 \%) .{ }^{24}$

Assess all ascitic fluid samples for color, consistency, cell count and differential, albumin, and total protein. These tests are usually sufficient to provide evidence regarding the cause of ascites. If there is suspicion of infection, order a gram stain and culture (80\% sensitivity for detecting an infection if obtained prior to initiation of antibiotics) ${ }^{25}$ and glucose, lactate dehydrogenase (useful to differentiate primary from secondary bacterial peritonitis), ${ }^{26}$ and amylase tests. Other tests such as cytology, acid-fast bacilli smear and culture, and triglyceride level should only be obtained if specific conditions are suspected based on high pretest probabilities.

Calculating serum ascites albumin gradient (SAAG) is recommended as it has been shown to better characterize ascitic fluid than total protein-based tests. ${ }^{27}$ SAAG is calcu- lated by subtracting the level of ascitic fluid albumin from serum albumin level (SAAG = serum albumin - ascitic fluid albumin). A $S A A G \geq 1.1 \mathrm{~g} / \mathrm{dL}$ is consistent with portal hypertension, ${ }^{28}$ with approximately $97 \%$ accuracy.

After calculating SAAG, look at total protein levels in ascitic fluid. Total protein concentration $\geq 2.5 \mathrm{~g} / \mathrm{dL}$ with SAAG $\geq 1.1 \mathrm{~g} / \mathrm{dL}$ has a $78.3 \%$ diagnostic accuracy in determining heart failure as the cause of ascites, with a sensitivity of $53.3 \%$ and specificity of $86.7 \% .{ }^{28}$ On the other hand, a value of total protein $<2.5 \mathrm{~g} / \mathrm{dL}$ indicates cirrhosis, liver failure, or acute hepatitis as the cause of fluid build-up..$^{29}$ Stepwise evaluation of SAAG and total protein and how they can point toward the most likely cause of ascites is presented in FIGURE $2 .^{27-29}$

\section{Management \\ Noninvasive measures}

Sodium restriction. The aim of treatment for uncomplicated clinically apparent ascites is sodium restriction and removal of fluid from the body. Dietary salt restriction is complicated, and care should be taken to properly educate patients. Salt restriction advised in the literature has shifted from a strict measure of $<2 \mathrm{~g} / \mathrm{d}^{30}$ to more moderate strategies (described below). ${ }^{18}$

The 2 main reasons for this easing of restriction are issues with patient compliance and concerns about adverse effects with aggressive salt-restricted diets. One study assessing patient compliance with a saltrestricted diet found that more than twothirds of the patients were noncompliant, ${ }^{31}$ and $65 \%$ of the patients incorrectly assumed they were following the plan, which suggests poor dietary education. ${ }^{31}$ Of the group that was compliant, $20 \%$ actually decreased their caloric intake, which can be detrimental in liver disease. ${ }^{31}$ Concerns have been raised that aggressive salt restriction along with diuretic use can lead to diureticinduced hyponatremia and renal failure. ${ }^{32}$ Current European Association for the Study of the Liver (EASL) guidelines recommend salt restriction to a more moderate degree (80-120 mmol/d of sodium). This is equiva-

\section{$>$}

\section{Calculating}

the serum

ascites albumin gradient better characterizes ascitic fluid than total proteinbased tests. 
FIGURE 2

\section{Using SAAG and total protein level to determine the cause of ascites ${ }^{27-29}$}

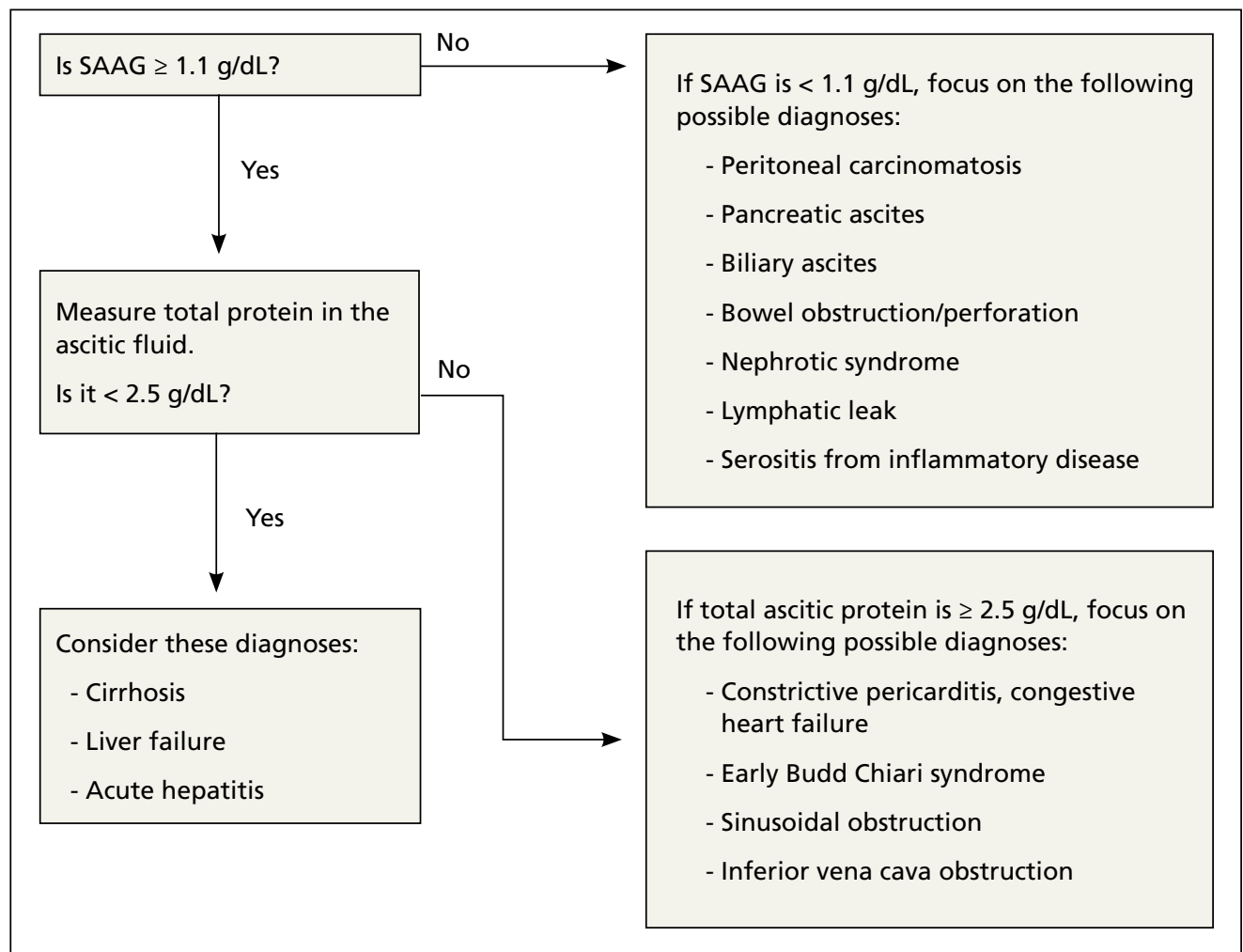

SAAG, serum ascites albumin gradient.

lent to 4.9-6.9 g of salt ( 1 tablespoon is roughly equivalent to $6 \mathrm{~g}$ or $104 \mathrm{mmol}$ of sodium). ${ }^{18}$

Diuretics. Initiation and dosage of diuretic therapy is a matter of some controversy. Historically, simultaneous administration of a loop diuretic and mineralocorticoid receptor blocker were recommended: $40 \mathrm{mg}$ furosemide and $100 \mathrm{mg}$ spironolactone, keeping the ratio constant with any dosage increases. This was based on a randomized controlled trial (RCT) showing that the combined diuretic therapy effectively mobilized ascites in a shorter period of time and with less frequent adverse effects (eg, hyperkalemia) compared with initial monotherapy. ${ }^{33}$

On the other hand, another study with more stable patients and relatively normal renal function showed that starting with a mineralocorticoid receptor blocker alone with sequential dose increments had equivalent benefit with no increase in adverse effects. ${ }^{34}$ Since the patient population in this study was more in line with what a PCP might encounter, we recommend following this guideline initially and keeping a close watch on serum electrolytes.

Usual maximum doses are spironolactone $400 \mathrm{mg} / \mathrm{d}$ and furosemide $160 \mathrm{mg} / \mathrm{d} .^{21,35}$ Adequate weight loss for patients with diffuse edema is at least $1 \mathrm{~kg} / \mathrm{d}$, per EASL guidelines. ${ }^{36,37}$ However, this might not be practical in outpatient settings, and a more conservative target of $0.5 \mathrm{~kg} / \mathrm{d}$ may be used for patients without significant edema. ${ }^{37}$

It is vital to get accurate daily weights and avoid excessive diuretic use, as it has been associated with intravascular volume depletion and acute kidney injury (25\%), hyponatremia $(28 \%),{ }^{38,39}$ and hepatic encephalopathy $(30 \%) .{ }^{40}$ Therefore, patients with acute kidney injury, hyponatremia, acute variceal hemor- 
rhage, or infection should also have their diuretics held until their creatinine returns to baseline.

\section{Invasive measures}

I Large-volume paracentesis. Patients with extensive and tense ascites should be treated initially with large-volume paracentesis, as this has been shown to predictably remove fluid more effectively than diuretics. ${ }^{38}$ This should be accompanied by albumin administration, $8 \mathrm{~g}$ for every liter of ascitic fluid removed if the total amount exceeds $5 \mathrm{~L}^{41}$ Following large-volume paracentesis, manage patients with the standard salt restriction and diuretic regimen. ${ }^{38}$ Serial large-volume paracentesis is a temporary measure reserved for a select group of patients who are intolerant to diuretics and are not candidates for a shunt.

I Transjugular intrahepatic portosystemic shunt (TIPS) is another option to control refractory ascites, but its benefit should be weighed against complications such as hepatic encephalopathy. An RCT found that TIPS with covered stents improved survival in patients with cirrhosis compared with regular large-volume paracentesis. ${ }^{42}$ Patients should be referred to hepatologists to make a determination about TIPS placement. Widely accepted contraindications for the placement of TIPS are decompensated cirrhosis (ChildPugh $>11$, model for end-stage liver disease $[\mathrm{MELD}]>18$ ), renal failure (serum creatinine $>3 \mathrm{mg} / \mathrm{dL}$ ), heart failure, porto-pulmonary hypertension, and uncontrolled sepsis. ${ }^{43} \mathrm{Re}-$ current or persistent hepatic encephalopathy (West Haven grade $\geq 2$ ) is also a contraindication. The West Haven scale is widely used to measure severity of hepatic encephalopathy, grading it from 1 to 4 , with 1 being mild encephalopathy characterized by lack of awareness and shorter attention span, and 4 indicating unresponsiveness or coma. ${ }^{44}$

\section{How to manage refractory ascites}

Fragile patients are those with refractory ascites that is either unresponsive to standard salt restriction and maximum-dose diuretic therapy or that results in a re-accumulation of ascitic fluid soon after paracentesis. ${ }^{45}$ Spe- cialist care is required to improve survival and quality of life for these patients. They should be referred to a hepatologist for consideration of TIPS placement or liver transplantation. ${ }^{18}$

Long-term use of albumin was tested in 2 trials for management of decompensated cirrhosis with ascites, yielding conflicting results. The ANSWER trial from Italy showed benefit with this treatment for prolonged survival. ${ }^{46}$ The other trial, from Spain, showed no benefit from albumin and midodrine administration for survival or for improving complications of cirrhosis. ${ }^{47}$ The contradictory results are likely due to heterogeneous populations in the 2 trials and differences in dose and duration of albumin administration. Hence, no clear recommendations can be made based on the available data; further research is needed.

\section{Getting a handle on bacterial peritonitis}

Bacterial peritonitis can be divided into spontaneous bacterial peritonitis (SBP) and secondary bacterial peritonitis. SBP is a common complication in patients with cirrhosis and occurs in around $16 \%$ of hospitalized patients, based on 1 study. ${ }^{48} \mathrm{SBP}$ is defined as a polymorphonuclear leukocyte count $\geq 250$ cells $/ \mu \mathrm{L}$ in the absence of a surgically treatable source of infection..$^{49}$ It is believed to be caused by bacterial translocation and is treated empirically with a third-generation cephalosporin. This treatment has been shown to be effective in $85 \%$ of patients. ${ }^{50}$

Patients with SBP are at a higher risk for renal impairment, likely resulting from increased cytokine production and decreased circulatory volume. ${ }^{51}$ Concomitant albumin administration has been shown to significantly improve outcomes and to reduce rates of hepatorenal syndrome in patients with serum creatinine $>1 \mathrm{mg} / \mathrm{dL}$, blood urea nitrogen $>30 \mathrm{mg} / \mathrm{dL}$, or total bilirubin $>4 \mathrm{mg} / \mathrm{dL} .{ }^{52}$ The recommended amount of albumin is $1.5 \mathrm{~g} / \mathrm{kg}$ given within 6 hours of SBP detection and repeat administration of $1 \mathrm{~g} / \mathrm{kg}$ on Day $3 .^{52}$

Guidelines from the American Association for the Study of Liver Diseases and from EASL recommend the long-term use of daily norfloxacin or trimethoprim-

\section{$>$}

Diuresis with mineralocorticoid inhibitors alone may be considered for new onset mild-to-moderate ascites in patients with normal renal function. 


\section{$>$}

Commonly used medications that should be avoided in patients with cirrhosis and ascites are angiotensinconverting enzyme inhibitors and angiotensin receptor blockers. sulfamethoxazole as secondary prophylaxis in patients who have survived an episode of SBP. ${ }^{18,30}$ Long-term antibiotic use is also justified for primary prophylaxis in cirrhosis patients who fulfill certain criteria: ascitic fluid protein $<1.5 \mathrm{~g} / \mathrm{dL}$ along with impaired renal function (serum creatinine $\geq 1.2 \mathrm{mg} / \mathrm{dL}$, blood urea nitrogen $\geq 25 \mathrm{mg} / \mathrm{dL}$, or serum sodium $\geq 130 \mathrm{mEq} / \mathrm{L}$ ) or with decompensated cirrhosis (Child-Pugh score $\geq 9$ and bilirubin $\geq 3 \mathrm{mg} / \mathrm{dL}){ }^{53}$ It has been shown to reduce the risk of SBP and hepatorenal syndrome, and improve overall survival. ${ }^{53}$

\section{Avoid these medications}

Commonly used medications that should be avoided in patients with cirrhosis and ascites are angiotensin-converting enzyme inhibitors and angiotensin receptor blockers. These agents block the action of angiotensin, which is a vital vasoconstrictor, and thereby cause a drop in blood pressure. This has independently been associated with poor outcomes in patients with cirrhosis. ${ }^{37}$

Nonsteroidal anti-inflammatory drugs (NSAIDs) are also relatively contraindicated in cirrhosis, as they can affect kidney function, induce azotemia, and reduce kidney sodium excretion. NSAIDs induce vasoconstriction of afferent arterioles in the kidneys, leading to a decreased glomerular filtration rate, further activating RAAS and sympathetic drive. This leads to increased sodium and water retention and worsening ascites. ${ }^{54}$

\section{Improve outcomes \\ by circling in a hepatologist}

PCPs can play a vital role in the prevention, treatment, surveillance, and home care of patients with cirrhosis who are at risk for ascites. $^{55}$ Referral of patients with hepatic impairment manifesting as unexplained abnormal liver function tests, new-onset ascites, and/or image findings consistent with cirrhosis to a hepatologist at least once is recommended. Such referrals have been shown to be associated with a better overall outcome. ${ }^{56}$ Patients with known cirrhosis leading to ascites can generally be managed at home with the assistance of specialists and specialized nurses. ${ }^{35}$

In a study from the University of Michi- gan, $69 \%$ of patients with cirrhosis had at least 1 nonelective readmission; $14 \%$ of patients were readmitted within 1 week, and $37 \%$ within 1 month. ${ }^{57}$ These are staggering statistics that highlight the gaps in care coordination and management of patients with cirrhosis in the outpatient setting. PCPs can play a vital role in bridging this gap.

A promising framework is suggested by a study from Italy by Morando et al in 2013. ${ }^{58}$ The researchers assessed a specialized health care model for cirrhotic patients and showed significant improvement in health care cost, readmission rate, and overall mortality when compared with the existing model of outpatient care. ${ }^{58}$

This was not a blinded study and there were concerns raised by the scientific community about its design. Because it was conducted in Italy, the results might not be fully applicable to the United States health care setting. However, it did show that better coordination of care leads to significantly better patient outcomes and reduces health care expenditure. Therefore, a more complete understanding of the disease process and latest literature by PCPs, communication with specialists, and comprehensive coordination of care by all parties involved is vital for the management of this patient population. JFP

\section{CORRESPONDENCE}

Muhammad Salman Faisal, MD, Cleveland Clinic Foundation, 9500 Euclid Avenue, Cleveland, OH 44195; faisalm@ccf.org

\footnotetext{
References

1. Runyon BA, Montano AA, Akriviadis EA, et al. The serumascites albumin gradient is superior to the exudate-transudate concept in the differential diagnosis of ascites. Ann Intern Med. 1992;117:215-220.

2. D'Amico G, Garcia-Tsao G, Pagliaro L. Natural history and prognostic indicators of survival in cirrhosis: a systematic review of 118 studies. J Hepatol. 2006;44:217-231.

3. Gordon FD. Ascites. Clin Liver Dis. 2012;16:285-299.

4. Schrier RW, Arroyo V, Bernardi M, et al. Peripheral arterial vasodilation hypothesis: a proposal for the initiation of renal sodium and water retention in cirrhosis. Hepatology. 1988;8:1151-1157.

5. Arroyo V, Terra C, Gines P. Advances in the pathogenesis and treatment of type-1 and type-2 hepatorenal syndrome. J Hepatol. 2007;46:935-946.

6. Bernardi M, Moreau R, Angeli P, et al. Mechanisms of decompensation and organ failure in cirrhosis: from peripheral arterial vasodilation to systemic inflammation hypothesis. J Hepatol. 2015;63:1272-1284.

7. Jalan R, Fernandez J, Wiest R, et al. Bacterial infections in cirrhosis: a position statement based on the EASL Special Conference 2013. J Hepatol. 2014;60:1310-1324.

8. Albillos A, Lario M, Álvarez-Mon M. Cirrhosis-associated immune dysfunction: distinctive features and clinical relevance. J Hepatol. 2014;61:1385-1396.
} 
9. Oey RC, van Buuren HR, de Man RA. The diagnostic work-up in patients with ascites: current guidelines and future prospects Neth J Med. 2016;74:330-335.

10. de Kerguenec C, Hillaire S, Molinié V, et al. Hepatic manifestations of hemophagocytic syndrome: a study of 30 cases. Am J Gastroenterol. 2001;96:852-857.

11. Milić S, Lulić D, Štimac D. Non-alcoholic fatty liver disease and obesity: biochemical, metabolic and clinical presentations. World J Gastroenterol. 2014;20:9330-9337.

12. Aron-Wisnewsky J, Clement K, Pépin J-L. Nonalcoholic fatty liver disease and obstructive sleep apnea. Metabolism. 2016;65: 1124-1135.

13. Li CP, Lee FY, Hwang SJ, et al. Spider angiomas in patients with liver cirrhosis: role of alcoholism and impaired liver function. Scand J Gastroenterol. 1999;34:520-523.

14. Cavanaugh J. Gynecomastia and cirrhosis of the liver. Arch Intern Med. 1990;150:563-565.

15. Karnath B. Stigmata of chronic liver disease. Hosp Phys. 2003;7:14-16,28.

16. Schipper HG, Godfried MH. [Physical diagnosis--ascites]. Ned Tijdschr Geneeskd. 2001;145:260-264.

17. Cattau EL, Jr., Benjamin SB, Knuff TE, et al. The accuracy of the physical examination in the diagnosis of suspected ascites. JAMA. 1982;247:1164-1166.

18. EASL clinical practice guidelines for the management of patients with decompensated cirrhosis. J Hepatol. 2018;69:406-460.

19. Runyon BA, AASLD Practice Guidelines Committee. Management of adult patients with ascites due to cirrhosis: an update. Hepatology 2009;49:2087-2107.

20. EASL Clinical practice guidelines: management of hepatocellular carcinoma. J Hepatol. 2018;69:182-236.

21. Runyon BA. Care of patients with ascites. New Engl J Med. 1994;330:337-342.

22. Sakai H, Sheer TA, Mendler MH, et al. Choosing the location for non-image guided abdominal paracentesis. Liver Int. 2005;25:984-986.

23. Mercaldi CJ, Lanes SF. Ultrasound guidance decreases complications and improves the cost of care among patients undergoing thoracentesis and paracentesis. Chest. 2013;143:532-538.

24. Ennis J, Schultz G, Perera P, et al. Ultrasound for detection of ascites and for guidance of the paracentesis procedure: technique and review of the literature. Int J Clin Med. 2014;5:1277-1293.

25. Runyon BA, Canawati HN, Akriviadis EA. Optimization of ascitic fluid culture technique. Gastroenterology. 1988;95:1351-1355.

26. Akriviadis EA, Runyon BA. Utility of an algorithm in differentiating spontaneous from secondary bacterial peritonitis. Gastroenterology 1990;98:127-133.

27. Hoefs JC. Serum protein concentration and portal pressure determine the ascitic fluid protein concentration in patients with chronic liver disease. J Lab Clin Med. 1983;102:260-273.

28. Farias AQ, Silvestre OM, Garcia-Tsao G, et al. Serum B-type natriuretic peptide in the initial workup of patients with new onset ascites: a diagnostic accuracy study. Hepatology. 2014;59: 1043-1051.

29. Gupta R, Misra SP, Dwivedi M, et al. Diagnosing ascites: value of ascitic fluid total protein, albumin, cholesterol, their ratios, serum-ascites albumin and cholesterol gradient. J Gastroenterol Hepatol. 1995;10:295-299.

30. Runyon BA. Management of adult patients with ascites due to cirrhosis: update 2012. AASLD Practice Guideline. Accessed April 28, 2021. www.aasld.org/sites/default/files/2019-06/ AASLDPracticeGuidelineAsciteDuetoCirrhosisUpdate2012 Edition4_.pdf

31. Morando F, Rosi S, Gola E, et al. Adherence to a moderate sodium restriction diet in outpatients with cirrhosis and ascites: a real-life cross-sectional study. Liver Int. 2015;35:1508-1515.

32. Bernardi M, Laffi G, Salvagnini M, et al. Efficacy and safety of the stepped care medical treatment of ascites in liver cirrhosis: a randomized controlled clinical trial comparing two diets with different sodium content. Liver. 1993;13:156-162.

33. Angeli P, Fasolato S, Mazza E, et al. Combined versus sequential diuretic treatment of ascites in non-azotaemic patients with cirrhosis: results of an open randomised clinical trial. Gut. 2010;59:98-104.

34. Santos J, Planas R, Pardo A, et al. Spironolactone alone or in combination with furosemide in the treatment of moderate ascites in nonazotemic cirrhosis. A randomized comparative study of efficacy and safety. J Hepatol. 2003;39:187-192.
35. Grattagliano I, Ubaldi E, Bonfrate L, et al. Management of liver cirrhosis between primary care and specialists. World J Gastroenterol. 2011;17:2273-2282.

36. Pockros PJ, Reynolds TB. Rapid diuresis in patients with ascites from chronic liver disease: the importance of peripheral edema. Gastroenterology. 1986;90:1827-1833.

37. EASL clinical practice guidelines on the management of ascites, spontaneous bacterial peritonitis, and hepatorenal syndrome in cirrhosis. J Hepatol. 2010;53:397-417.

38. Gines P, Arroyo V, Quintero E, et al. Comparison of paracentesis and diuretics in the treatment of cirrhotics with tense ascites. Results of a randomized study. Gastroenterology. 1987;93: 234-241.

39. Salerno F, Badalamenti S, Incerti P, et al. Repeated paracentesis and i.v. albumin infusion to treat 'tense' ascites in cirrhotic patients. A safe alternative therapy. J Hepatol. 1987;5:102-108.

40. Sola R, Vila MC, Andreu M, et al. Total paracentesis with dextran 40 vs diuretics in the treatment of ascites in cirrhosis: a randomized controlled study. J Hepatol. 1994;20:282-288.

41. Bernardi M, Caraceni P, Navickis RJ, et al. Albumin infusion in patients undergoing large-volume paracentesis: a meta-analysis of randomized trials. Hepatology. 2012;55:1172-1181.

42. Bureau C, Thabut D, Oberti F, et al. Transjugular intrahepatic portosystemic shunts with covered stents increase transplantfree survival of patients with cirrhosis and recurrent ascites. Gas troenterology. 2017;152:157-163.

43. Fagiuoli S, Bruno R, Debernardi Venon W, et al. Consensus conference on TIPS management: techniques, indications, contrain dications. Dig Liver Dis. 2017;49:121-137.

44. Ferenci P, Lockwood A, Mullen K, et al. Hepatic encephalopathy-definition, nomenclature, diagnosis, and quantification: final report of the working party at the 11th World Congresses of Gastroenterology, Vienna, 1998. Hepatology. 2002;35: 716-721.

45. Salerno F, Guevara M, Bernardi M, et al. Refractory ascites: pathogenesis, definition and therapy of a severe complication in patients with cirrhosis. Liver Int. 2010;30:937-947.

46. Caraceni P, Riggio O, Angeli P, et al. Long-term albumin administration in decompensated cirrhosis (ANSWER): an open-label randomised trial. Lancet. 2018;391:2417-2429.

47. Solà E, Solé C, Simón-Talero M, et al. Midodrine and albumin for prevention of complications in patients with cirrhosis awaiting liver transplantation. A randomized placebo-controlled trial. J Hepatol. 2018;69:1250-1259.

48. Fasolato S, Angeli P, Dallagnese L, et al. Renal failure and bacterial infections in patients with cirrhosis: epidemiology and clinical features. Hepatology. 2007;45:223-229.

49. Hoefs JC, Canawati HN, Sapico FL, et al. Spontaneous bacterial peritonitis. Hepatology. 2007;2:399-407.

50. Felisart J, Rimola A, Arroyo V, et al. Cefotaxime is more effective than is ampicillin-tobramycin in cirrhotics with severe infections. Hepatology. 1985;5:457-462.

51. Lenz K, Kapral C, Gegenhuber A, et al. Systemic, renal, and hepatic hemodynamic derangement in cirrhotic patients with spontaneous bacterial peritonitis. Hepatology. 2004;39: with sp

52. Sigal SH, Stanca CM, Fernandez J, et al. Restricted use of albumin for spontaneous bacterial peritonitis. Gut. 2007;56:597-599.

53. Fernández J, Navasa M, Planas R, et al. Primary prophylaxis of spontaneous bacterial peritonitis delays hepatorenal syndrome and improves survival in cirrhosis. Gastroenterology. 2007;133:818-824.

54. Boyer TD, Zia P, Reynolds TB. Effect of indomethacin and prostaglandin $\mathrm{Al}$ on renal function and plasma renin activity in alcoholic liver disease. Gastroenterology. 1979;77:215-222.

55. Grattagliano I, Ubaldi E, Portincasa P, et al. Liver disease: early signs you may be missing. J Fam Pract. 2009;58:514-521.

56. Bini EJ, Weinshel EH, Generoso R, et al. Impact of gastroenterology consultation on the outcomes of patients admitted to the hospital with decompensated cirrhosis. Hepatology. 2001;34: 1089-1095.

57. Volk ML, Tocco RS, Bazick J, et al. Hospital readmissions among patients with decompensated cirrhosis. Am J Gastroenterol. 2012;107:247-252.

58. Morando F, Maresio G, Piano S, et al. How to improve care in outpatients with cirrhosis and ascites: a new model of care coordination by consultant hepatologists. J Hepatol. 2013;59: 257-264.

\section{NSAIDs are relatively contraindicated in cirrhosis as they can affect kidney function, induce azotemia, and reduce kidney sodium excretion.}

